\title{
Experimental and Numerical Analysis of Bubbles Distribution Influence in BubbleDeck Slab under Harmonic Load Effect
}

\author{
Ali Sabah Mahdi \\ Department of Civil Engineering \\ University of Baghdad \\ Baghdad, Iraq \\ ali.sabah@esraa.edu.iq
}

\author{
Shatha Dheyaa Mohammed \\ Department of Civil Engineering \\ University of Baghdad \\ Baghdad, Iraq \\ shatha.dh@coeng.uobaghdad.edu.iq
}

\begin{abstract}
Reducing a structure's self-weight is the main goal and a major challenge for most civil constructions, especially in tall buildings and earthquake-affected buildings. One of the most adopted techniques to reduce the self-weight of concrete structures is applying voids in certain positions through the structure, just like a voided slab or BubbleDeck slab. This research aims to study, experimentally and theoretically, the structural behavior of BubbleDeck reinforced concrete slabs under the effect of harmonic load. Tow-way BubbleDeck slab of $2500 \mathrm{~mm} \times 2500 \mathrm{~m} \times 200 \mathrm{~mm}$ dimensions and uniformly distributed bubbles of $120 \mathrm{~mm}$ diameter and $160 \mathrm{~mm}$ spacing $\mathrm{c} / \mathrm{c}$ was tested experimentally under the effect of harmonic load. Numerical analysis was also performed with the ABAQUS software. The results of the adopted numerical model were in acceptable agreement with the experimental results. The numerical analysis presented by the bubbles distribution effect was carried out for the BubbleDeck two-way slab under the effect of harmonic load through the evaluated numerical model. Two cases were considered in which the distribution kept the critical positions of the slab free from the bubbles. The results proved that bubbles distribution significantly affected the structural behavior.
\end{abstract}

\section{Keywords-distribution of bubbles; resonance frequencies}

\section{INTRODUCTION}

A concrete slab is usually a horizontal flat plate with parallel top and bottom surfaces. Generally, slabs are supported by reinforced concrete beams (commonly, it is cast monolithically with slabs), by reinforced concrete walls, by masonry walls, by structural steel members, directly by columns, or continuously by ground [1]. BubbleDeck is a construction technology adopted in many industrial projects nowadays [2]. It was invented by Jorgen Bruenig in the 1990s, who developed the first biaxial hollow slab (known as BubbleDeck now) [3]. BubbleDeck slab system uses recycled plastic hollow balls to eliminate concrete that has no significant structural effect from the solid slab so that the slab self-weight can be reduced to a significant extent $(30 \%$ to $50 \%)$, thus reducing the loads transferred to the whole building [3]. The dynamic load is a load that changes in its magnitude, direction, and position with time. Structures are usually subjected to at least one type of dynamic load during their service life. When an applied load varies as a sine or a cosine function, it is termed as harmonic loading. The vibration developed by an unbalanced rotating machine, the vertical motion of an automobile on a sinusoidal road surface, and a tall chimney's oscillations due to vortex shedding in a steady wind are all examples of harmonic motion [4].

\section{LITERATURE REVIEW}

Authors in [5] carried out a theoretical study about the structural behavior of BubbleDeck slab. The solid slab was modeled as pure concrete thick shells, while the BubbleDeck slab was modeled as a layered shell. BubbleDeck slab was modeled with three layers, two (top and thin bottom) layers of standard concrete, and one intermediate rectangular layer of hollow spheres made from recycled High-Density Poly Ethylene (HDPE). Ten $\mathrm{kN}$ live loads were applied upon both types of models. The results of the finite element analysis were compatible with the primary analysis and the experimental results. It was found that the bending stresses of BubbleDeck slab were smaller than that of the solid slab by $6.43 \%$. BubbleDeck slab deflection was greater than that of the solid slab by $5.88 \%$ due to the descent of the slab stiffness caused by the presence of the hollow portion. The analysis results also showed that BubbleDeck slab's shear resistance was $60 \%$ that of the same thickness's solid slab. Vertical reinforcement can be provided to solve this problem. The self-weight of the BubbleDeck slab was found to be the $35 \%$ of the solid slab. Authors in [6] studied the effects of a moving harmonic load on beams with different boundary conditions. Several parameters were considered such as support type, excitation frequency, and speed of the harmonic load. All the beams under study were homogeneous, isotropic, and initially at rest. All of them were subjected to concentrated harmonic forces of constant amplitudes.

\section{FINITE ELEMENT ANALYSIS}

Integrodifferential equations and partial differential equations have been recognized to be better solved by the Finite Element Method (FEM). Therefore, FEM has become the numerical method most preferred in solving many 
engineering and applied science field problems. Since FEM needs a minimal amount of training and versatile computer programs, it became more recommended for solving different practical problems [7]. During the last three decades, rapid development in computer-aided and finite element techniques provided an economical solution to perform many accepted 3D structural analyses. To investigate the overall behavior and analysis of the BubbleDeck slab, the finite element software ABAQUS/CAE 6.14.1/2019, was utilized. ABAQUS is a suite of engineering simulation programs that depends on FEM [9]. It can solve problems that include various types of simple linear analysis and the most challenging nonlinear simulations [8]. For the performed modeling, three parts were necessary to be generated. The first part represented the BubbleDeck slab that was modeled with a tetrahedral element. The second part was the steel-reinforcement which was modeled as wires. The third part was the steel support that was modeled as a solid sweep. The details of these parts are shown in Figures 1-3. After creating the specimen parts, the material properties were defined and suitable interaction ways between all specimen's components were selected. An assembly module process was considered to perform the achieved model geometry by creating part instances, then sample proportions were placed in the global coordinate system, as shown in Figure 4. Along the contact surface between the steel support and the concrete slab, tie interaction was applied. The steel support surface was considered as a master surface while the concrete surface was the slave. For interface conditions between the steel reinforcement and concrete, embedded interaction was considered.

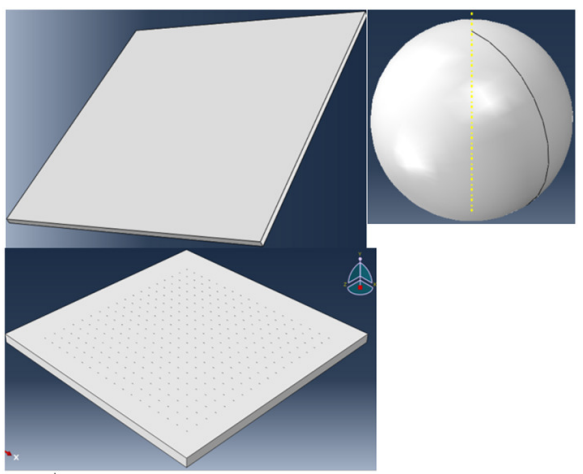

Fig. 1. Modeling of the BubbleDeck slab.

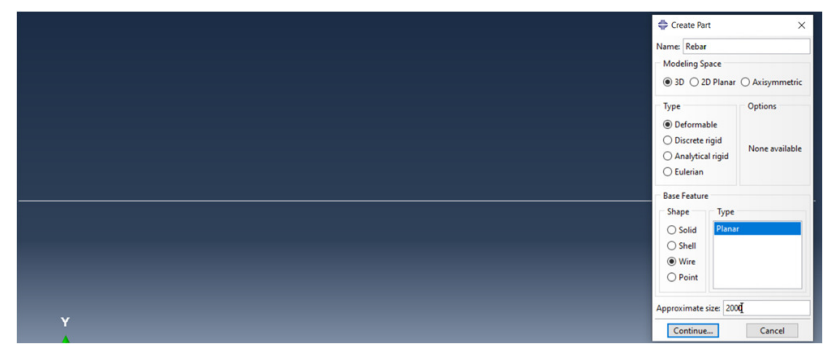

Fig. 2. Model of the reinforced steel.

To simulate the experimental conditions of the harmonic load in FEA, a harmonic load of characteristics compatible with that of the experimental test was applied on the mid surface (Figure 5). The considered mesh size was $20 \mathrm{~mm}$ for all the parts of the model, while the adopted element types included tetrahedron, truss, and quad-dominated elements for the BubbleDeck slab, steel-reinforcement and steel support respectively as shown in Figures 6-8.

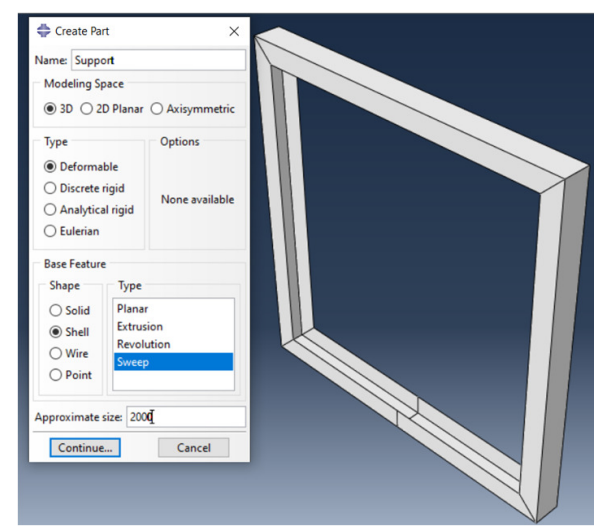

Fig. 3. Modeling of steel support.

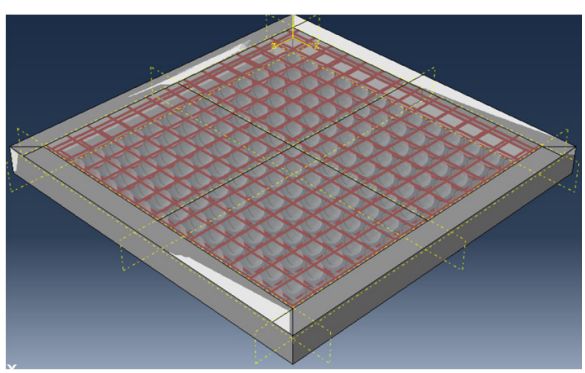

Fig. 4. Assembly model of the BubbleDeck slab.

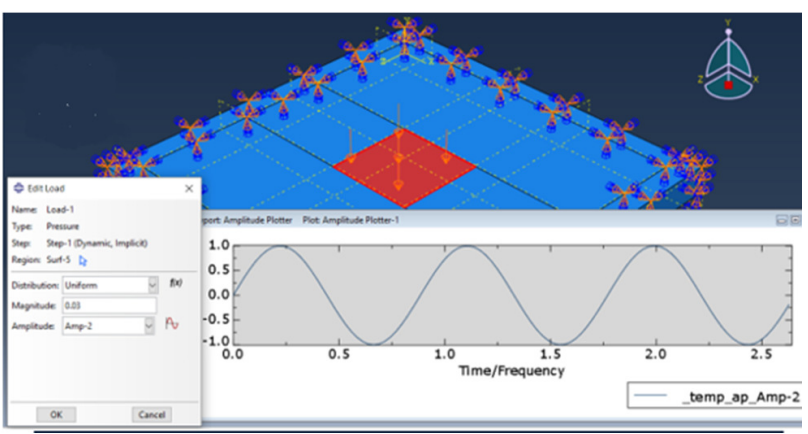

Fig. 5. Harmonic load application.

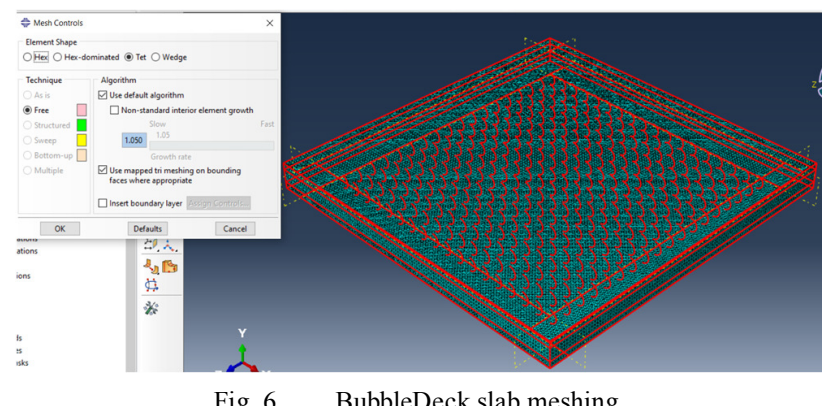

Fig. 6. BubbleDeck slab meshing. 


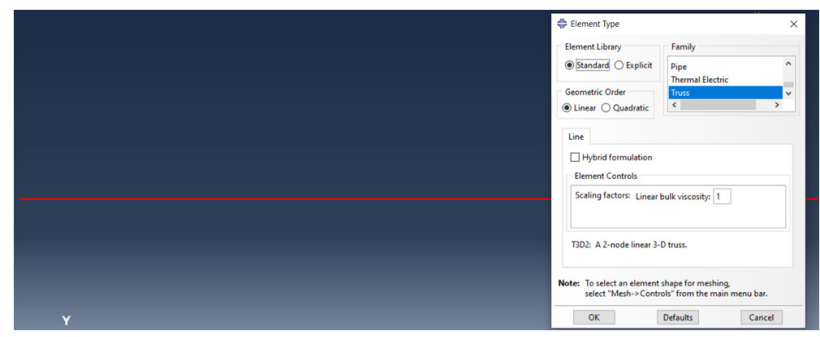

Fig. 7. Steel reinforcement meshing.

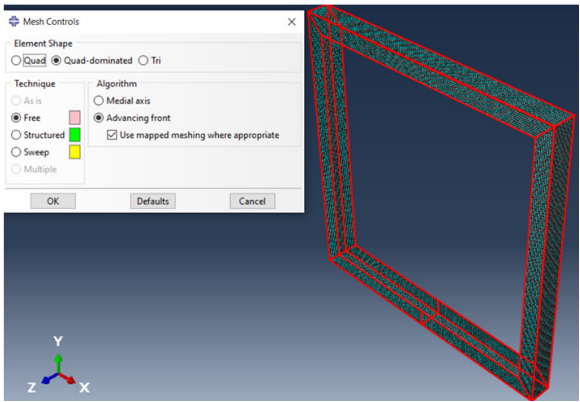

Fig. 8. Steel support meshing.

\section{NUMERICAL APPLICATION AND DISCUSSION}

\section{A. Verification of the Finite Element Model}

For verification purposes, a comparison between the experimental and the numerical results was considered for only one specimen (Model I - Figure 9 and Table I).

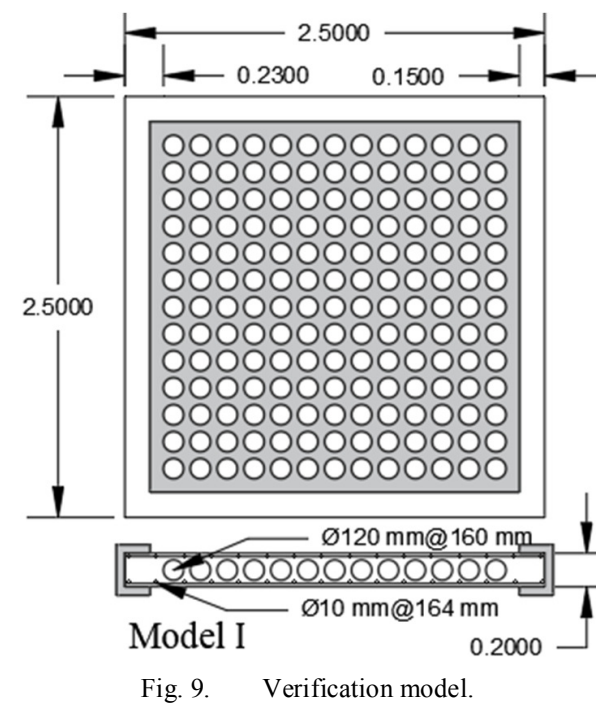

TABLE I. DETAILS OF THE ADOPTED PARAMETRIC STUDY

\begin{tabular}{|c|c|c|c|c|c|}
\hline Specimen & $\begin{array}{c}\text { Bubble } \\
\text { diameter } \\
(\mathbf{m m})\end{array}$ & $\begin{array}{c}\text { Spacing between } \\
\text { bubbles c/c } \\
(\mathrm{mm})\end{array}$ & $\begin{array}{c}\mathrm{S} \\
(\mathrm{mm})\end{array}$ & $\begin{array}{l}\text { Number } \\
\text { of bubbles }\end{array}$ & $\begin{array}{c}\text { Volume } \\
\text { reduction } \\
(\%)\end{array}$ \\
\hline Model I & \multirow{3}{*}{120} & 160 & 290 & 169 & 15.6 \\
\hline Model II & & 140 & 270 & \multirow{2}{*}{160} & \multirow{2}{*}{15} \\
\hline Model III & & 150 & 290 & & \\
\hline
\end{tabular}

The harmonic load of various frequencies was applied upon the experimental specimen. Data were recorded with a laser indicator and an ultra-sonic piezo device to measure the vertical vibration and the applied harmonic load of the different frequencies. The adopted dynamic load in this study is harmonic (Figures 10-11).

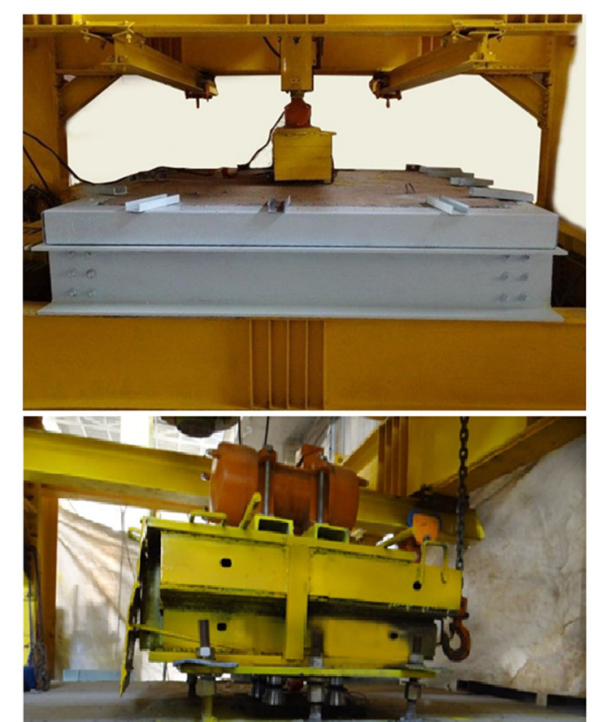

Fig. 10. Experimental harmonic load.

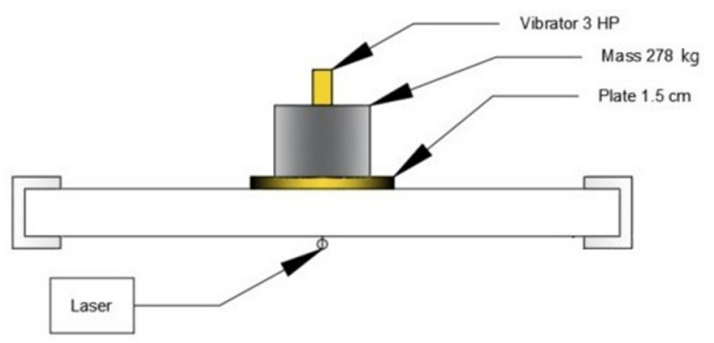

Fig. 11. Test set-up.

Generally, the mathematical formula of this load consists of two main parts. The first characterizes the amplitude of the harmonic load $\left(2 m e w_{0}^{2}\right)$ while the second represents the sine wave $\left(\sin \left(w_{0} t\right)\right)[10]$ :

$$
P_{d}=2 m e w_{0}^{2} \sin \left(w_{0} t\right)
$$

where $P_{d}$ is the induced harmonic dynamic load $(\mathrm{N}), m$ is the eccentric rotating mass $(\mathrm{kg}), e$ is the eccentric distance $(\mathrm{m})$, and $w_{0}$ is the operating frequency of the machine $(\mathrm{Hz})$. Table II shows the details of the considered cases of the harmonic load.

TABLE II. AMPLITUDE OF THE HARMONIC LOAD.

\begin{tabular}{|c|c|}
\hline Operating frequency (Hz) & Amplitude (kN) \\
\hline 5 & 13.90 \\
\hline 6 & 20.02 \\
\hline 7 & 27.24 \\
\hline 8 & 35.58 \\
\hline 9 & 45.04 \\
\hline 10 & 55.60 \\
\hline 15 & 125.10 \\
\hline 20 & 222.40 \\
\hline 25 & 347.50 \\
\hline \multicolumn{2}{|l}{} \\
\hline
\end{tabular}


The build-up numerical model's evaluation process under dynamic load was established to compare the maximum amplitude response as illustrated in Table III. The verification process showed that when the FEA outputs regarding vibration amplitude were compared with the experimental results, they improved the validity and significantly of the adopted finite element model. The difference percentage for Model I was $8.3 \%$.

TABLE III. EXPERIMENTAL AND FEA RESULT COMPARISON FOR MAXIMUM AMPLITUDE UNDER HARMONIC LOAD

\begin{tabular}{|c|c|c|c|}
\hline \multirow{2}{*}{$\begin{array}{c}\text { Frequency } \\
(\mathbf{H z})\end{array}$} & \multicolumn{2}{|c|}{ Maximum amplitude (mm) } & \multirow{2}{*}{$\begin{array}{c}\text { Error } \\
(\mathbf{\%})\end{array}$} \\
\cline { 2 - 3 } & Experimental & FEA & \\
\hline 5 & 1.1 & 1.05 & 4.5 \\
\hline 6 & 1.2 & 1.12 & 6.67 \\
\hline 7 & 1.3 & 1.2 & 7.69 \\
\hline 8 & 1.2 & 1.1 & 8.3 \\
\hline 9 & 0.85 & 0.8 & 5.9 \\
\hline 10 & 0.8 & 0.78 & 2.5 \\
\hline 15 & 0.6 & 0.57 & 5 \\
\hline 20 & 0.45 & 0.43 & 4.4 \\
\hline 25 & 0.35 & 0.33 & 5.7 \\
\hline
\end{tabular}

\section{B. Parametric Study}

An investigation study was conducted, that considered the bubbles arrangement influence on the structural behavior of BubbleDeck slab in dynamic states. The specimen in Model I was selected to characterize the uniform bubbles arrangement case where the bubbles number was 169 (Figure 9). This slab was analyzed experimentally and theoretically. This study includes two bubbles arrangements, both of the same bubbles diameter and concrete volume reduction, and with different bubbles distributions as shown in Table I. The main difference in bubbles distribution between the specimens in Model II and Model III is the adopted clear distance from the fixed-end supports to the adjacent bubbles' first raw. The specimen in Model II was designed to have such bubble arrangement that the first raw of the bubbles was far from the fixed support by $270 \mathrm{~mm}$ while this distance was enlarged in Model III to $290 \mathrm{~mm}$. The distance between the bubbles was selected to be compatible with [11]. Since the adopted concrete volume reductions were less than $20 \%$, the traditional slab design can be adopted for BubbleDeck slab [11]. The slab was designed to carry a uniform distribution load of 120 ton.
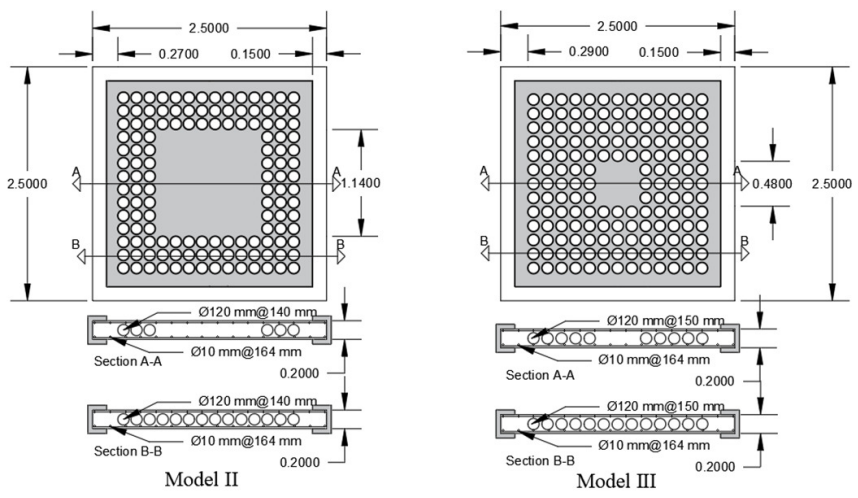

Fig. 12. Adopted bubbles distributions (Model II and Model III).
On the other hand, no bubbles were allocated in the middle part of these specimens. The center area of a square shape was selected to be solid with a side length of 1.14 and $0.48 \mathrm{~m}$ for Model II and Model III respectively (Figure 12). It is well known that for a fixed-end slab, the critical position can be presented at central and fixed-end locations (maximum moment generation). Hence, providing a solid section in these locations will modify the structural behavior of the BubbleDeck slab.

\section{Dissociation}

In this part of the numerical analysis, the harmonic load's effect upon the BubbleDeck slab of the adopted bubbles arrangement was inspected. The investigation comprised of studying the dynamic response concerning the natural frequencies and the deflection time history. Table IV illustrates the natural frequencies of the three studied bubbles distribution models. The outcomes improved the achieved modification regarding the gained natural frequencies. Model II specimen was characterized by optimum distribution with a modification percentage reaching $19.6 \%, 24.4 \%$, and $23.8 \%$ respectively for the three considered modes. This refers to the enhancement of the dynamic characteristics (stiffness and mass) that were attained by the redistribution of bubbles. Figure 13 shows the layout of the first three considered modes.

(a)

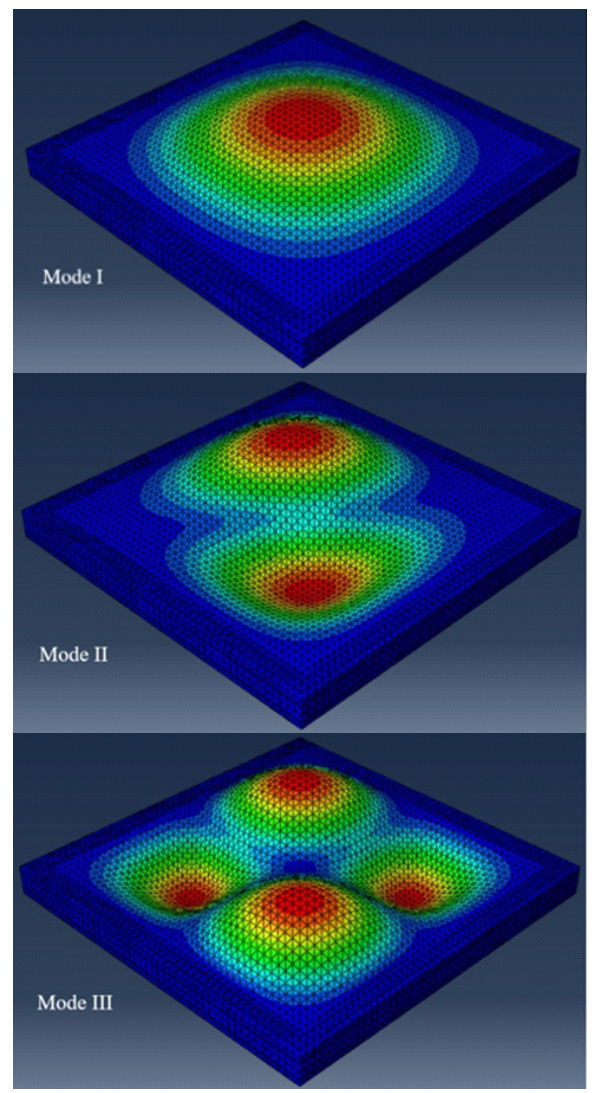

Fig. 13. Modes of harmonic load: (a) Mode I, (b) Mode II, (c) Mode III.

The results of this analysis indicated that Model II specimen was the most strong under the effect of harmonic 
load. The maximum response of this specimen was not more than $0.5 \mathrm{~mm}$, while the specimen of uniform bubbles distribution (Model I) reached $1.0 \mathrm{~mm}$ for the first $0.2 \mathrm{~s}$ of loading time. Moreover, it was also clear that load time duration significantly affected the strength reduction during the load time (Figure 14 and Table V).

TABLE IV. NATURAL FREQUENCIES

\begin{tabular}{|c|c|c|c|c|c|}
\hline \multirow{2}{*}{ Modes } & \multicolumn{3}{|c|}{ Natural frequencies (Hz) } & \multicolumn{2}{c|}{ Modification \% } \\
\cline { 2 - 6 } & Model I & Model II & Model III & Model II & Model III \\
\hline Mode I & 6.7 & 8.01 & 7.9 & 19.6 & 17.9 \\
\hline Mode II & 12.6 & 15.68 & 15.1 & 24.4 & 19.8 \\
\hline Mode III & 18.38 & 22.76 & 21.8 & 23.8 & 18.6 \\
\hline
\end{tabular}

TABLE V. VARIATION IN THE VIBRATION AMPLITUDE

\begin{tabular}{|c|c|c|c|c|c|c|c|}
\hline \multirow{2}{*}{ Models } & \multicolumn{7}{|c|}{ Vibration amplitude (mm) } \\
\cline { 2 - 8 } & $\begin{array}{c}\text { 1st } \\
\text { cycle }\end{array}$ & $\begin{array}{c}\text { 2nd } \\
\text { cycle }\end{array}$ & $\begin{array}{c}\text { 3rd } \\
\text { cycle }\end{array}$ & $\begin{array}{c}\text { 4th } \\
\text { cycle }\end{array}$ & $\begin{array}{c}\text { 5th } \\
\text { cycle }\end{array}$ & $\begin{array}{c}\text { 6th } \\
\text { cycle }\end{array}$ & $\begin{array}{c}\text { 7th } \\
\text { cycle }\end{array}$ \\
\hline Mode I & 0.91 & 1.16 & 1.23 & 1.29 & 1.38 & 1.46 & 1.56 \\
\hline Mode II & 0.5 & 0.25 & 0.42 & 0.24 & 0.39 & 0.28 & 0.35 \\
\hline Mode III & 0.69 & 0.79 & 0.91 & 1.02 & 1.15 & 1.26 & 1.36 \\
\hline
\end{tabular}

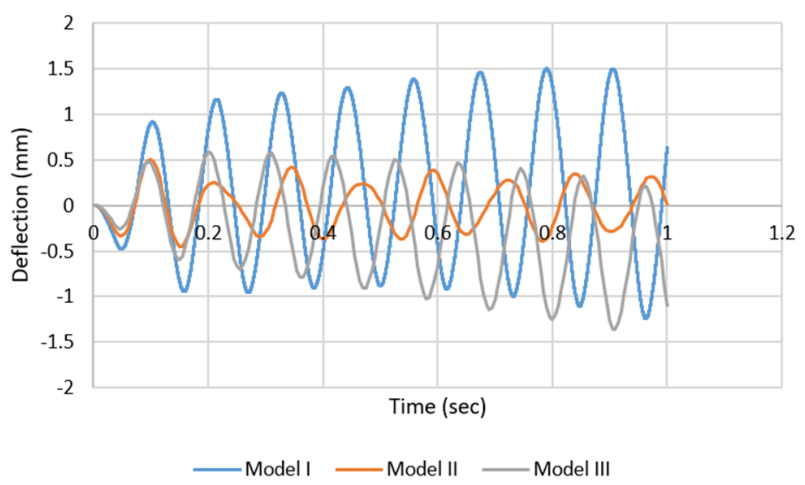

Fig. 14. Vibration-time history for the adopted models.

\section{CONCLUSION}

After comparing the experimental and theoretical studies to ensure that the BubbleDeck slab's modeling is adequate, nonlinear finite element analysis was carried out using the ABAQUS/Standard 2019 to analyze the two-way BubbleDeck slabs adopted in the current study. After a satisfying agreement between the experimental and the theoretical results, the analysis of the tested BubbleDeck slabs with some important parametric studies was also conducted, and the following points were deducted:

- The constituent materials, the element type for concrete and reinforcing steel, and the modeling of the connection between the specimen parts and the support adopted in the numerical analysis are in good agreement with the experimental work.

- According to the considered parametric study, the bubbles distribution was highly affected upon the dynamic response of the BubbleDeck slab.

\section{REFERENCES}

[1] A. Nilson, D. Darwin, and C. Dolan, Design of Concrete Structures, 14th ed. Boston, MA, USA: McGraw-Hill Education, 2009.
[2] B. G. Bhade and S. M. Barelikar, "An experimental study on two-way bubble deck slab with spherical hollow balls," International Journal of Recent Scientific Research, vol. 7, no. 6, pp. 11621-11626, Jun. 2016.

[3] M. Pandey and M. Srivastava, "Analysis of Bubble Deck Slab Design by Finite Element Method," - International Journal of Science Technology \& Engineering, vol. 2, no. 11, pp. 599-606, May 2016.

[4] R. W. Clough and J. Penzien, Dynamics of Structures, Subsequent edition. New York, NY, USA: McGraw-Hill College, 1975.

[5] P. P. Teja, P. V. Kumar, S. Anusha, C. Mounika, and P. Saha, "Structural behavior of bubble deck slab," in IEEE-International Conference On Advances In Engineering, Science And Management (ICAESM -2012), Nagapattinam, Tamil Nadu, India, Mar. 2012, pp. 383-388.

[6] M. Abu-hilal and M. Mohsen, "The vibration of beams with general boundary conditions due to a moving harmonic load," Journal of Sound and Vibration, vol. 232, no. 4, pp. 703-717, May 2000, https://doi.org/ 10.1006/jsvi.1999.2771.

[7] N.-H. Kim, Introduction to Nonlinear Finite Element Analysis. New York, NY, USA: Springer, 2014.

[8] "Getting Started with Abaqus: Interactive Edition (6.10)," Abacus 6.10. http://130.149.89.49:2080/v6.10/books/gsa/default.htm? startat=ch01s02. html (accessed Dec. 20, 2020).

[9] Abaqus Analysis User's Guide Volume IV: Elements. Waltham, MA, USA: Dassault Systemes, 2014.

[10] B. M. Das and G. V. Ramana, Principles of Soil Dynamics, 2nd ed. Stamford, CT, USA: CL Engineering, 2010.

[11] "BubbleDeck Voided Flat Slab Technical Manual \& Documents." BubbleDeck, Jun. 2008. 